\title{
Reformas Policiales y Narrativas Institucionales en Argentina: Renombrando Escuelas de Policía*
}

\author{
Mariana Sirimarco \\ Universidad de Buenos Aires (UBA), Buenos Aires, Argentina
}

\section{INTRODUCCIÓN: EL CASO Y EL CONTEXTO}

$\mathrm{E}$ 14 de abril de 2011, la entonces Ministra de Seguridad de la Nación Argentina, Dra. Nilda Garré, firmó la resolución 167/2011, dictaminando el cambio de nombre de las tres escuelas de la Policía Federal Argentina (PFA) ${ }^{1}$. Así, la Escuela Superior de Policía “General de Brigada Cesario Ángel Cardozo" pasó a llamarse "Comisario General Enrique Fentanes", la Escuela de Cadetes "Coronel Ramón Lorenzo Falcón" pasó a denominarse "Comisario General Juan Ángel Pirker" y la Escuela de Suboficiales y Agentes "Comisario General Alberto Villar", "Don Enrique O'Gorman".

Tal movimiento político debe entenderse como enmarcado en otro de mayor alcance: la creación del Ministerio de Seguridad², a raíz de un intenso conflicto con el gobierno de la ciudad de Buenos Aires por los violentos desalojos ocurridos en un espacio público ocupado por familias carenciadas en el barrio de Villa Soldati. En esa oportunidad, el jefe de gobierno porteño, Mauricio Macri, intimó al Poder Ejecutivo Nacional a hacerse cargo, a través de la $\mathrm{PFA}^{3}$, del desalojo del predio, construyendo un discurso xenófobo al vincular la ocupación con la inmi-

\footnotetext{
* Una versión preliminar de este trabajo fue presentada al 54 Congreso Internacional de Americanistas (ICA), realizado en Viena del 15 al 20 de julio de 2012.

DADOS - Revista de Ciências Sociais, Rio de Janeiro, vol. 56, no-3, 2013, pp. 605 a 633.
} 
gración y el narcotráfico. La "recuperación del espacio público", según palabras de dicha autoridad porteña, dejó innumerables heridos y tres muertos, víctimas de la represión policial y el enfrentamiento entre vecinos de la zona.

El conflicto reavivó la siempre candente problemática de la seguridad ciudadana y aceleró una reestructuración del mapa político nacional, obligando a la creación de un espacio con peso propio en relación a la materia. Así, lo que antes era sólo una dependencia del Ministerio de Justicia, Seguridad y Derechos Humanos, pasó a convertirse en un nuevo Ministerio, que agrupa, bajo su égida, la dirección y coordinación de funciones y jurisdicciones de las fuerzas policiales y de seguridad provinciales y nacionales (Policía Federal Argentina, Gendarmería Nacional, Prefectura Naval Argentina, Policía de Seguridad Aeroportuaria).

La creación del nuevo Ministerio de Seguridad fue anunciada el 10 de diciembre de 2010, en el acto por el Día Universal de los Derechos Humanos. La fecha, lejos de ser fortuita, abre un campo de significación, propiciando la clave según la cual debe leerse tal medida. En dicho acto, transmitido en cadena nacional, la presidenta de la Nación, Cristina Fernández de Kirchner, argumentaba: "Muchas veces han querido - no sé si con intenciones o tal vez por falta de comprensión - hacernos aparecer que como creemos en los derechos humanos no nos importa la seguridad, como si las dos cosas no estuvieran íntima y directamente ligadas. Cada vez que se ha violado un derecho humano se ha creado más inseguridad y más violencia en todas las sociedades"4.

El discurso y la nueva cartera ministerial no sólo surgían contestando el reclamo originado en la administración porteña, sino que asentaban, sobre la grafía de lo dicho, una política de estado. Argumentaban que es imposible una política adecuada en materia de seguridad fuera del marco de respeto a los derechos humanos. La designación de la entonces Ministra de Defensa ${ }^{5}$ como titular del nuevo Ministerio de Seguridad no hizo sino reforzar esta aseveración, al poner al frente de éste a una persona con un perfil comprometido en la temática de los derechos humanos y cuyo desempeño en la anterior cartera estuvo signado por un intento de modernización y democratización del ámbito castrense y de una mayor articulación de éste con la sociedad.

Muchos de los nombramientos dentro de la nueva cartera ministerial se enmarcaron en esta misma lógica, pues implicaron la designación 
de reconocidos profesionales en el área de la seguridad que provenían del ámbito de las ciencias sociales y humanísticas. Así, y sólo por mencionar un par de ejemplos, la abogada Ileana Arduino - otrora investigadora del "Centro de Estudios Legales y Sociales" (CELS) y del "Instituto de Estudios Comparados en Ciencias Penales y Sociales" (INECP), que se desempeñaba como Directora Nacional de los Derechos Humanos y el Derecho Internacional Humanitario en el Ministerio de Defensa - fue nombrada al frente de la Secretaría de Políticas de Prevención y Relaciones con la Comunidad. El abogado Gustavo Palmieri, de amplia experiencia en el CELS y en la Organización de Naciones Unidas (ONU), fue designado subsecretario de Gestión y Bienestar del Personal de las Fuerzas Policiales y de Seguridad de la Secretaría de Seguridad Operativa. Al frente de la Subsecretaría de Delitos Complejos y Lucha contra la Criminalidad Organizada quedaba el policía Miguel Ángel Robles, anteriormente jefe de la División Telefonía de la Policía Judicial, quien - según reza la información levantada por los diarios - al investigar la muerte de su padre, acaecida en 1975, descubrió que lo había matado la propia fuerza de seguridad y no un atentado montonero ${ }^{6}$, como versaba la "historia oficial".

Es en este marco político y social que, a cuatro meses de la creación del Ministerio de Seguridad, la Ministra a cargo anunciaba, entre otras medidas ${ }^{7}$, el decreto que cambiaría los nombres de las escuelas de la $\mathrm{PFA}^{8}$. El cambio ponía sobre el tapete cuestiones de poder y subordinación de lo policial a la esfera socio-política, profundizando el mensaje de una institución policial democrática. La nueva denominación intentaba subrayar, a modo de homenaje, "la trayectoria de personas que han contribuido con su accionar a proteger la vida, las libertades, los derechos y las garantías de los ciudadanos" (Resolución 167/2011). Los viejos nombres debían ser reemplazados. Lo que equivale a decir que las personas que los portaban debían dejar de oficiar como "héroes institucionales". Falcón, Villar y Cardozo perdían así su lugar de relevancia en el horizonte policial (y social). El decreto obligando a nuevas denominaciones no sólo intentaba borrar esos nombres de la escena pública. Más aun: los cuestionaba en tanto portadores legítimos de valores institucionales viables.

Puede argumentarse que los cambios estructurales, los reacomodamientos organizacionales, los pases a retiro, las nuevas designaciones y los renombramientos no son elementos novedosos en materia de intervención o reforma policial. Constituyen, antes bien, los movimien- 
tos muchas veces remanidos con que se aborda el intento de una nueva política gubernamental. La discusión acerca de su eficacia y su intencionalidad tiene larga data: ¿se trata de medidas destinadas a fomentar cambios de fondo o meras disposiciones superficiales para remedar (pero no ejercer) un cambio sustantivo?

Ya se trate de uno u otro caso (o de una combinación de ambos), mera recurrencia de tales medidas pone de manifiesto la potencia de lo semántico como herramienta de acción política. Los nombres que se eligen o los nombres que se descartan (sea de funcionarios, de policías, de escuelas o de dependencias) refuerzan el intento de instaurar, en la arena policial, otra narrativa. Es decir, otros elementos significantes - hechos, sitios, personajes, acciones - a partir de los cuales reestructurar las coordenadas del mapa policial. En estos contextos de reformas policiales, los intentos de renarrativización no pasan desapercibidos.

Tal fue el caso de lo sucedido a partir de la resolución 167/2011. Unos días después de anunciada tal medida, la Dra. Andrea Palomas Alarcón, perteneciente a la asociación civil "Abogados por la Justicia y la Concordia", escribía en una página web:

Concomitante con el retiro del busto del comisario Villar que se encontraba en el patio de honor del Departamento Central de Policía, han sido cambiados los nombres de tres escuelas de la Policía Federal.

Acusados de "represores de Estado", fueron archivados en el arcón del ultraje kirchnerista los nombres de Ramón L. Falcón, Alberto Villar y Cesáreo Cardozo.

Se necesita una gran cuota de cinismo para trocar en victimarias a víctimas del terrorismo y es que existe un verdadero hilo conductor del enojo oficial hacia el homenaje a Falcón, Villar y Cardozo: los tres fueron asesinados por bombas terroristas.

Si en algo nunca nos faltó el kirchnerato, es en prodigarnos su cinismo a prueba de balas.

Los Jefes asesinados son víctimas que molestan porque prueban que los "jóvenes idealistas" no hacían la revolución con una margarita en la mano.

Ramón Lorenzo Falcón

Hizo la carrera militar retirándose con el grado de Coronel y luego fue diputado nacional. A diferencia de la actual Ministro de Seguridad Nilda Garré, Falcón nunca tuvo un cargo en un gobierno de facto.

Fue nombrado Jefe de Policía por el Presidente Constitucional Figueroa Alcorta. 
Se lo conoció como un Jefe de Policía duro, todo un represor, en los tiempos en que ésa no era una mala palabra. Actuaba para un gobierno democrático surgido de las urnas y no tenía complejo de culpa al hacer cumplir la ley (...)

Alberto Villar

El comisario general Alberto Villar fue egresado de la escuela de Cadetes Ramón L. Falcón. En el año 1973 pasó a retiro.

Cuenta una anécdota que el general Perón lo hizo llamar por considerarlo el mejor jefe policial. Pese a que se hallaba en retiro efectivo lo convocó a su casa de Gaspar Campos.

Villar asistió sin mucho entusiasmo y preparándose para rechazar el ofrecimiento dijo "General, usted sabe que yo no soy peronista...". Franqueza brutal.

El Presidente en ejercicio le respondió: “Usted sabe bien, comisario, que no lo convoco porque sea o no peronista, sino que lo convoco porque LA PATRIA LO NECESITA...".

Perón fue el Presidente Constitucional que inició la lucha contra la subversión.

Villar fue asesinado por Montoneros. Los servicios de inteligencia de Montoneros, cuyos pilares eran Rodolfo Walsh y Horacio Verbitsky, averiguaron que la nave del comisario Villar había entrado a reparaciones, en los astilleros "Astarsa".

Fue designado un pelotón de cinco integrantes para perpetrar el atentado, entre ellos el buzo táctico Alfredo Nicoletti. Éste sería el encargado de poner debajo de la embarcación de Villar una bomba sumergida que lo mató junto con su esposa.

Villar era la síntesis de la represión de las bandas armadas marxistas. Era profundamente odiado por los montoneros por haber clausurado el diario de propaganda montonera "Noticias" dirigido por Miguel "Cogote" Bonasso y haberles enviado un desafío propio del que sabe que tiene los días contados: "ellos tienen un cajón para mí pero yo tengo varios para ellos" (...)

Juan Ángel Pirker

(...) La cartera gubernamental declara que Pirker "fue destacado jefe policial de la democracia entre 1986 hasta su fallecimiento en 1989. Pirker fue un firme batallador de la integración de la institución con la sociedad, con el respeto a los derechos humanos como estandarte de su gestión...".

Lejos de mi ánimo está la intención de quitar méritos al Jefe Pirker, que fue un hombre decente y un gran policía, pero Pirker no nació en 1986. 


\section{Mariana Sirimarco}

Pirker hizo su carrera policial durante todo el gobierno militar que tanto odio despierta en este gobierno.

Varios de los subalternos directos de Pirker, policías de la Federal, se encuentran presos por delitos de lesa humanidad en Devoto, Marcos Paz, y en varias provincias argentinas (...)

Decir que Pirker es un defensor de los derechos humanos y condenar a sus subordinados por violaciones a los mismos es tan absurdo como los juicios que los retienen presos. ¿Desconoce la Ministro la cadena de mandos? ${ }^{9}$

En días posteriores, el escritor y filósofo José Pablo Feinmann también dejaba su opinión, en el diario Página/12:

Luego, en un acto sencillamente conmovedor y de un gran coraje, Garré cambió los nombres de las Escuelas de Policía. Que la ministra de un gobierno quite a una Escuela de Policía el nombre de Alberto Villar a mí me conmueve. Acaso porque sé muy bien quién fue ese señor y sé que la brutalidad, la vejación y la tortura sin límites es lo único que podría enseñarse al amparo de su nombre. La paradoja fascinante de todo esto es que al torturador formado por la Escuela de la Doctrina Francesa de la Seguridad Nacional y por la Escuela de las Américas lo puso el general Perón al frente de la Federal, alegando que era "un buen policía". Luego, policías con su mismo espíritu le pusieron su nombre a una escuela, para honrarlo. Ahora, Garré, peronista de pura cepa, quita el nombre del criminal paranoico que el viejo líder del movimiento había elegido para emprender una matanza clandestina de opositores políticos de izquierda. Como ya no se quiere matar a nadie, sino que se propugna una sociedad en que los conflictos puedan elaborarse dentro de la democracia, ese nombre va al tacho de los malos recuerdos (...) Garré, en cambio, a Villar lo destituye. Ninguna escuela va a llevar el nombre del tipo que con una tanqueta rompió la puerta del Partido Justicialista en 1972 porque ahí velaban a los muertos de la Base Almirante Zar. Estos actos de este gobierno tienen una trascendencia difícil de mensurar. Lo único que uno sabe es que ningún otro los haría. Que jamás habría esperado ver estas cosas. Y que está preparado para ver otras ${ }^{10}$.

En los días siguientes al anuncio y ejecución de la citada resolución, cualquiera podía encontrarse, ya fuera en los diarios o en portales de internet, con opiniones - como las aquí rescatadas - tan contrarias como tajantes. La medida pareció tocar un punto neurálgico en la sociedad argentina; la renominación de las escuelas policiales hizo aflorar pareceres y posicionamientos incapaces de quedar a medio tono. 
La opinión pública parecía construirse en torno a una alineación binaria que suscitaba adhesión o rechazo, ambos igualmente fervorosos ${ }^{11}$.

Hasta la nota más "informativa" fue seguida de comentarios de lectores incapaces de sustraerse al fuego cruzado. Fue casi imposible abordar la lectura de cualquier foro de opinión sin toparse con alusiones que intentaban funcionar como explicativas - peronismo, montoneros, guerrilleros, criminales, comandante Teresa ${ }^{12}$ - y cuya carga valorativa dependía del credo político del enunciador (o de su posicionamiento en relación al gobierno). El entendimiento de la medida oscilaba, sin grises intermedios, entre el tacho de los malos recuerdos o el arcón del ultraje kirchnerista. El debate popular parecía no poder escapar de la lógica de bandos: de una historia narrada en relación a dos demonios ${ }^{13}$, donde la medida gubernamental de hoy sólo podía ser codificada como la continuidad de la militancia política de entonces.

En este arco maniqueo de entendimiento, la valoración de tal medida política resultaba indisociable de sus gestores. El peso de la resolución se agigantaba por ser su responsable directa una peronista de pura cepa - con todo lo que ello quiere significar. Sobre esta amalgama indisoluble del qué y del quién se alzaron las voces que celebraban la reparación o denunciaban la revancha, preocupadas por declarar el reemplazo de los nombres de las escuelas policiales como ejercicio de resarcimiento o de borramiento de la historia.

El alto impacto que suscitó tal medida revela el fuerte componente de lucha política que tiene toda conmemoración, donde la intencionalidad de guardar memoria implica, necesariamente, la intencionalidad de fijar una determinada versión del pasado (Jelin, 2007). Los posicionamientos elevados a partir de la resolución 167/2011 no hacen sino demostrar hasta qué punto lo acaecido durante los años 1970 sigue vertebrando, con sentidos ya sea disputados o aprovechados, las lecturas actuales de la política y la historia. Dicha resolución no puede entenderse, seguramente, fuera del contexto de posibilidad construido tanto por las políticas estatales que se han venido llevando a cabo en torno a esta temática, como por la sensibilidad pública que ellas despiertan. Es de este clima de época que la resolución mencionada extrae su carácter de contienda simbólica.

Este trabajo busca detenerse en el análisis de este renombramiento en cuanto disputa, exponiendo el entramado de sentidos sobre el que éste se construye y se valida. Sostener esta postura implicará argumentar 
que las palabras "hacen" a la creación y al sostén de relaciones y situaciones sociales, en tanto comunican identidades y permiten una determinada experimentación de la realidad, articulando así concepciones de la historia y la memoria en el debate colectivo.

Escribir analíticamente sobre la coyuntura siempre es una tarea ardua. Debo advertir entonces que este trabajo no pretende agotar su descripción, ni apuntar a una narración hilvanada o certera de la historia reciente. Tanto los materiales que se consultan, como las voces que se rescatan, no intentan sino trabajar con los pocos trazos - de la historia, de la memoria - que están en el común de la sociedad. El objetivo no es desentrañar la "verdad", sino indagar los hilos del relato. Será por ello comprensible que este trabajo abra más interrogantes que los que cierre. Tal hecho deberá ser visto, antes que como una falencia, como un signo de la complejidad del asunto abordado.

\section{EL RENOMBRAMIENTO DE LA REPRESIÓN A LOS DERECHOS HUMANOS}

Comprender cabalmente este proceso de renombramiento - comenzar a desentrañar los hilos de la trama - implica esbozar brevemente la trayectoria profesional de los funcionarios policiales que daban nombre, hasta la actualidad, a las escuelas de policía. Si dichas trayectorias se construyen, a continuación, a grandes rasgos, es porque el objetivo no es exponer biografías exhaustivas, sino señalar algunos puntos relevantes y por todos conocidos. El que así lo sea no hace sino reforzar la tesis que se desarrollará en este trabajo, poniendo de manifiesto la fortaleza de la vinculación entre historia y memoria.

El Coronel Ramón Lorenzo Falcón fue jefe de la entonces Policía de la Capital (luego PFA) de 1906 hasta su muerte, en 1909. Creó el Cuerpo de Cadetes y se caracterizó por su dureza y represión a los movimientos obreros del momento. Fue asesinado por el anarquista Simón Radowitzky, cuando volvía en carruaje del funeral de un policía. El Comisario General Alberto Villar fue director de la Escuela de Suboficiales y Agentes desde 1967 a 1970 y Jefe de la PFA durante 1974, año de su muerte. Propulsó la Alianza Anticomunista Argentina (AAA), un grupo de extrema derecha que llevó a cabo infinidad de secuestros y asesinatos durante la última dictadura militar (1976-1983). Fue asesinado por la agrupación Montoneros ${ }^{14}$, que colocó una bomba en su embarcación en el Tigre. El General de Brigada Cesario Cardozo fue jefe de la PFA en 1976, comenzada la dictadura. Ideólogo de la represión instau- 
rada en ese entonces, fue asesinado por Ana María González, de la agrupación Montoneros, con una bomba debajo de su cama.

Falcón, Villar, Cardozo. Hasta aquí, brevemente, los hechos de sus vidas. No los hechos totales, es claro, sino aquellos sobre los que giran las distintas versiones de la historia. Pues en el continuum que va desde Feinmann a Palomas Alarcón, lo que importa no es tanto el "dato crudo" - nombres, cargos, obras, fechas - sino la argamasa de sentido con que se lo recubre. Basta volver a las palabras de éstos, a sus relatos, para entender que lo que se detalla es, en su factualidad, más o menos lo mismo. Lo que difiere, en todo caso, es la comprensión que se hace de ella. Esto es, la trama de sentidos donde se ubica ese dato y del que ese dato, finalmente, extrae su valor. En la distancia que media entre considerar a estos jefes policiales como víctimas o victimarios, como cumplidores de la ley o como torturadores, lo que se dirime es, en definitiva, la significación y la apropiación de la historia.

Sobre esta capacidad de las palabras de ser portadoras de sentido es que opera la resolución 167 / 2011, cuestionando, en un mismo movimiento, no sólo la carga simbólica que conllevan los nombres de Falcón, Villar y Cardozo, sino el posicionamiento institucional que implica la elección de tales nombres para designar, en su momento, a las escuelas policiales. Esto es, la elección, entre todos los nombres posibles, de justamente esos tres. Si en el ejercicio de otorgar identidad lo que se homenajea es una determinada amalgama de situaciones y características, entonces es válido preguntarse cuáles son, concretamente, los rasgos que se resaltan al destacar estos nombres.

La respuesta es sencilla. Basta consultar cualquier historia oficial policial para que, ni bien aparecido uno solo de estos nombres, surjan a continuación, de modo indefectible, los restantes. Sus vidas y sus muertes se unen en un mismo hilo conductor:

La muerte del Comisario General Villar, fue el segundo caso de asesinato de Jefes de Policía; luego en el año 1976 acaecería la muerte del General Ángel Cesáreo Cardozo.

El primer hecho ocurrido el 15 de noviembre de 1909 tuvo como víctima al Coronel Ramón Lorenzo Falcón, quien en circunstancias que se trasladaba en su coche oficial, fue atacado por un anarquista que le arrojó una poderosa bomba que terminó con su vida y la de su secretario Juan Alberto Lartigau.

(...)

DADOS - Revista de Ciências Sociais, Rio de Janeiro, vol. 56, nº 3, 2013 
Esta horrenda trilogía de trágicos fallecimientos de Jefes de Policía Federal que se hallaban en plena actividad, tienen, además de un sino común, una semejanza en sus causas y trascendencias.

Todos habían expresado en sus dichos y accionar cuán profundamente estaban decididos a combatir al enemigo de la Patria; ya sea éste ácrata, anarquista o marxista o de cualquier signo ideológico extremo que representara ser un agente del desorden del caos o el materialismo ateo y anarquizante.

(...)

Estos tres ejemplos fundamentales de vidas entregadas al servicio de la Patria en los campos militar y policial nos hablan a las claras del noble sacerdocio que resulta el ser policía, cuando en una entrega total aplicamos en su punto exacto las palabras de Cristo "Nadie da más, que aquel que da su vida por sus semejantes".

No hay manifestación de vida trascendente, sin mártires (Muñoz, 1984:99-100).

El anterior extracto deja entrever, claramente, las razones del homenaje a Falcón, a Villar, a Cardozo. Se trata, en primer lugar, de jefes de la fuerza, a menudo provenientes del ámbito castrense ${ }^{15}$. Se trata, además, de oficiales ligados a la represión policial (contra "anarquistas", obreros o "subversivos"). Pero se trata, sobre todo, de policías muertos, cada uno de ellos, por atentados caracterizados como "terroristas". Es claro que la institución policial elige, de entre todos los nombres y personajes posibles, aquellos capaces de condensar un colectivo moral. Las vidas de Falcón, Cardozo y Villar (y más que nada sus muertes) esbozan, en pocos pero significativos trazos, el mensaje institucional. Dureza, lucha contra el crimen, muertes gloriosas en pos de esa misma lucha. Sus nombres evocan los condimentos que la agencia policial considera necesarios para que sus vidas se transformen en relatos.

Podría decirse que el mito institucional se escribe con pocas palabras: asesinato, víctimas, enemigo, anarquista, marxista, mártires. Esa es la historia que se cuenta, desde el relato oficial, cada vez que los nombres se evocan: el policía muere asesinado, los anarquistas y marxistas son asesinos, el policía es una víctima. Las vinculaciones con la represión y las dictaduras militares son soslayadas o, más bien, subsumidas en el relato institucional qua combate al enemigo de la Patria. 
El renombramiento de las escuelas policiales busca justamente intervenir en este campo semántico, impugnando esta interpretación de la historia y cotejándola con otra lectura y otro entendimiento. Esta medida claramente política apunta a marcar dos hechos fundamentales: que, en el contexto político actual, ni Falcón, ni Villar, ni Cardozo deben ser conceptualizados como personas relevantes y que, concordantemente, sus figuras no deben ser materia de honra pública.

La resolución 167 / 2011 propone nuevos nombres para las escuelas policiales, enfatizando los aportes profesionales de las nuevas figuras, sin mencionar jamás el por qué del rechazo a las antiguas. Sobra tal explicación, desde el momento en que se aduce que "el Estado debe construir una sociedad donde todos sus espacios y en particular las instituciones formadoras proclamen valores democráticos y el respeto a los derechos humanos". La resolución 167/2011 dice, por omisión, que aquellos héroes policiales no eran sino villanos.

La decisión política estriba entonces en proponer, para dichas escuelas, nombres de policías que no susciten tales asociaciones. Así, los perfiles profesionales de Enrique O'Gorman, Enrique Fentanes y Juan Ángel Pirker avanzan por otros terrenos semánticos ${ }^{16}$. El primero se desempeñó al mando de la Jefatura de la Policía de la capital de 1867 a 1874, elaborando el Reglamento General del Departamento de Policía y creando el Cuerpo de Vigilantes. En su accionar se destaca la remisión inmediata de la aplicación de barras y cepos a los detenidos en comisarías, por considerarlos instrumentos de tortura. El Comisario General Enrique Fentanes fue un reconocido teórico policial, contribuyendo a sentar las bases para la creación de la PFA en 1943. Docente y autor de diversas publicaciones, su labor permitió la creación de la Escuela Superior de Policía (1935), de la Biblioteca Policial y de la Revista de Policía y Criminalística de Buenos Aires. El Comisario General Juan Ángel Pirker fue jefe de la PFA en los primeros años de la reinstauración democrática, desde 1987 hasta 1989, año de su muerte. Tuvo por directriz el respeto a los derechos humanos y la integración de la institución policial con la sociedad, haciendo del servicio a la comunidad su bandera. Falleció trabajando en el edificio de la Jefatura ${ }^{17}$.

Es claro entonces que la sustitución de nombres y personajes apunta a la sustitución de campos semánticos. Al policía de la dictadura militar se le opone el policía erudito. Al creador de la yunta brava ${ }^{18}$ se le contrapone el instaurador de una policía integrada a la ciudadanía. El organi- 
zador de la tortura estatal sistematizada es enfrentado con su objetor. La dictadura se reemplaza con democracia; la mano dura, con derechos humanos. No abundan, en los nuevos homenajeados, ni atentados, ni muertes violentas, ni asesinatos. La narrativa institucional no deja de construirse, pero merced ahora a otros simbolismos. La intencionalidad política de renominar implica la intencionalidad política de reconfigurar el relato. Implica, en una palabra, la intencionalidad mayor de coconstruirlo y resignificarlo.

Hablar de nominación es hablar de tramas sociales. Como advierte Foley (1992), las palabras no pueden ocurrir más que en contexto: la adopción de una categoría determinada no es fortuita, sino que obedece a la inscripción de una persona o una institución en un determinado universo ético y moral. Lo que equivale a decir que los nombres - para remitirnos al caso que nos ocupa - son hechos sociales siempre situados (Tonkin, 1980; Herzfeld, 1982).

Todo nombre se asienta en estas tramas sociales; su permanencia revela una red de relaciones. Los estudios clásicos sobre parentesco bien nos han enseñado que los nombres no son sino uno de los modos de inscribir a una persona en el seno de un grupo de filiación. Similar afirmación puede realizarse, creo yo, en relación a la designación institucional, donde el nombre no hace más que ubicarla - a la Escuela, a la policía - en relación a un determinado segmento del linaje policial. Elegir un nombre es optar por un campo de pertenencia sobre otro, puesto que el nombre se posiciona estableciendo líneas políticas, trazando una continuidad histórica. El acto de nominar actúa añadiendo un nuevo eslabón a un entramado social preexistente.

Acceder al sentido del nombre, a esa pluralidad de voces y valores que se arremolinan en su seno, implica interrogarse acerca del acto mismo de nominar. Si nombrar una escuela equivale a otorgarle una identidad determinada, si bautizar una institución implica consagrarla, en virtud de esa denominación, dentro de un sistema de filiación dado, ¿qué espectro de significación se abre con el nombre conferido?, ¿qué acordes resuenan en el nombre que se vuelve homenaje? O lo que es lo mismo, ¿a quién se recuerda y por qué?

Me gustaría ilustrar lo hasta aquí argumentado a través de un caso paradigmático. Esto es, a través de una de las escuelas mencionadas y de aquel policía que se festeja en su nombre: la Escuela de Suboficiales y Agentes, el Comisario General Alberto Villar. Proponer tal ejercicio es- 
conde dos razones fundamentales. La primera: la posibilidad de visualizar, en el mayor detalle que admite el análisis de un caso, lo que es material de todos en general. La segunda: la posibilidad de sostener que las trayectorias profesionales son, como las narrativas biográficas, fuentes de información sobre contextos sociales (Spivak L'Hoste, 2010). Asomarse a la trayectoria profesional de este jefe policial que fue Alberto Villar permitirá entonces sacar a la luz esa matriz de prácticas, valores y posicionamientos que hizo de su nombre un mapa semántico. Y permitirá demostrar que todo acto de nominación es, finalmente, un instrumento de inmenso poder para la reproducción de discursos sociales.

\section{UN CASO PARADIGMÁTICO: EL COMISARIO GENERAL ALBERTO VILLAR}

La Escuela de Suboficiales y Agentes de la PFA fue nombrada en honor al Comisario General Alberto Villar el 1 de diciembre de $1974^{19}$. Se cumplía, en ese entonces, un mes exacto de su asesinato. Fue por ello que, según reza la historia institucional, "respetando el sentir de la mayoría de los integrantes de la institución y teniendo en cuenta que había sido director del Instituto, la jefatura dispuso (...) dar el nombre del ilustre mártir a esta escuela" 20 .

Con esa simple acción se inauguraba un relato. Toda institución los construye: narrativas que ponen en escena discursos, vivencias y valorizaciones a partir de los cuales pensarse como grupo social y como institución. Dichos relatos institucionales condensan significados: cuentan una historia que se presume por todos compartida, instituyen una gama de sentidos que deberán traducirse en entendimientos totales. Dicen, a propios y extraños, quién y cómo se es. Construir un relato implica así construir una versión de la realidad, donde la verificación empírica y la necesidad lógica ceden terreno ante la "necesidad narrativa", y donde la interpretación de los hechos prima por sobre su descripción (Bruner, 1991; Ochs y Capps, 1996).

El relato institucional construido en torno a la figura de Villar opera en este sentido. No se trata de una mera reunión de sucesos ni de la descripción aséptica de un evento. Se trata, más bien, de la transformación de un acontecimiento en un mensaje, de la cristalización, si se quiere, de un hecho en un ejemplo (Sirimarco, 2010). De allí que lo importante de un relato no sea tanto si se ajusta o no a la "realidad", sino la realidad que conforma. Dicho de otro modo, el relato importa no para cali- 
brar la divergencia entre la realidad fáctica y su narración, sino para reparar en cómo se expresa el sentir institucional.

Se entenderá entonces que lo que sigue a continuación no puede - ni pretende - ser una biografía de Villar, sino tan sólo el rescate de algunos de los trazos inmortalizados de su vida. Esto es, de algunos de los elementos que transformaron su trayectoria profesional en narrativa. En tanto relato, huelga repetirlo, no importa ya la verdad de los hechos, sino su enunciación. Son estos sentidos institucionalizados los que permiten, dentro del ámbito policial, construir el mito. Son también sentidos institucionalizados - otros - los que permiten denostarlo. Es el diálogo entre unos y otros el que configura, finalmente, la posibilidad del homenaje y la causa del renombramiento.

En 1984, el comisario retirado Jorge Muñoz escribe un libro acerca de la vida de Alberto Villar. Según consta en la contratapa, el autor había sido, durante diez y seis años, su ayudante. Esta clase de publicación no es ajena a la fuerza policial. Desde antiguo, numerosos relatos, cuentos, memorias y biografías escritas por su personal han ganado la calle para dejar constancia de un cierto relatar institucional. En este ejercicio de resaltar valores o ensalzar comportamientos, dichos relatos funcionan como ejemplos moralizantes: el racconto de escenas que ilustran la tradición policial y las distintas experiencias de sus miembros sirve, al modo de las parábolas bíblicas o las leyendas, para la incorporación de valores y prácticas institucionales (Ford, 2003; Sirimarco, 2010).

El libro de Muñoz se ubica en esta senda. En el de las biografías que intentan un rescate moral; que se proponen no sólo dar a conocer, sino sobre todo ensalzar. Su obra no persigue otro fin que el de brindar homenaje, en un momento (¿de reiniciación democrática? ¿de juicio a las juntas militares?) en el que "el testimonio de su vida y el mensaje de su vocación [de Villar] cobran hoy mayor vigencia" (Muñoz, 1984:12). Por lo que dice, por la semblanza que realiza, por la historia que construye, la vida de Villar se vuelve, en la pluma de su otrora asistente, un discurso. Para decirlo una vez más: se vuelve un relato institucional.

Ya desde temprano, asegura Muñoz, Villar va a dar muestras de aquello que será el resumen de su vida. Completada su instrucción y flamante policía en la comisaría 44, Villar se destacará "por su espíritu de sacrificio y dedicación, evidenciado en procedimientos que permitieron desbaratar las actividades de extremistas políticos". Si, como 
sostiene Cavallaro (2000), toda vida se narra hacia atrás, rescatando selectiva y parcialmente las memorias del pasado (o más bien produciéndolas), hace bien Muñoz en señalar que estos primeros episodios profesionales contienen ya el germen de lo que será su desempeño todo. En ellos es posible "vislumbrar el sino de una lucha cuyos objetivos serían combatir la delincuencia y el terrorismo e imponer el orden" (Muñoz, 1984:26).

El tiempo pasa; se suceden obras y méritos. Villar es destinado, en 1952, a la custodia del entonces presidente Juan Domingo Perón. Luego es pasado a disponibilidad, a raíz de un incidente con un miembro allegado al círculo del poder ejecutivo. Vuelve a la actividad a finales de 1953, cumpliendo servicio en el Despacho de Investigaciones. Es director de la Escuela de Suboficiales y Agentes desde 1967 a 1969. Se retira voluntariamente de la institución en marzo de 1973, cumplidos treinta años de servicio y habiendo luchado, como siempre, con dedicación y sacrificio, contra el terrorismo. Esa lucha incluye un papel activo en la organización, a comienzos de esa década, de las primeras brigadas antiguerrilleras.

Y aquí, podría decirse, es donde empieza la "historia". O mejor dicho, donde cierta construcción de la memoria señala su inicio. En enero de 1974, a causa de un ataque del Ejército Revolucionario del Pueblo (ERP) a una guarnición militar,

Perón citó en forma reservada a Villar, quien concurrió a la quinta presidencial de Olivos en horas de la noche. Allí el Presidente sin dar muchos rodeos le ofreció el cargo de Subjefe de Policía.

Villar era conocido como un profesional sin identificación política alguna, que había tenido que actuar en todos los gobiernos del siempre cambiante panorama argentino. Ello fue su mejor aval, pues sin haberse identificado con ninguna línea, le cabía perfectamente que fuera requerido como el más eficaz y menos propenso a ser influenciable.

Villar hizo hincapié en ello diciendo:

- General, Ud. sabe muy bien que yo he pertenecido a su custodia pero nunca fui afiliado.

- Eso ahora no tiene importancia, Villar; es la Patria quien lo necesita -enfatizó Perón.

- General, conozco la gravedad de la situación y a ese llamado no me puedo negar; cuente conmigo.

- Gracias Villar, sabía que me iba a acompañar -respondió aliviado Perón (Muñoz, 1984:64). 
Profesional sin identificación política, concurrente veloz al llamado de la Patria, Villar es promovido al grado de Comisario General y ocupa en abril de 1974 la jefatura de la PFA, por renuncia de su titular. En agosto de ese año se organiza oficialmente la Triple A, bajo su supervisión. En noviembre muere asesinado en la localidad de Tigre, a bordo de su crucero "Marina", bautizado en honor a su esposa:

Su sueño de navegante de las islas había desvelado a los miembros de su custodia. La intención de hacerlo desistir de la compra de la embarcación en momentos tan poco oportunos no había tenido éxito. Tampoco, lograr que aceptara amarrarlo en puerto vigilado. Resultaba imposible convencerlo de que superara su natural obstinación a que las custodias invadieran su ya deteriorada intimidad. Apelando a la fortaleza de su carácter y dominado por el aspecto más negativo del valor, la temeridad, no admitió vigilancia alguna en la lancha o sus cercanías, aduciendo que se le quitaría esa porción de vida privada que tanto anhelaba, y suponiendo que pasaría más desapercibido, evitando ostentosos desplazamientos (Muñoz, 1984:952). (...)

Tras cargar los bultos, Villar ponía en marcha el motor, mientras el oficial encargado de su custodia en tierra insistía en acompañarlo, providencialmente sin ser aceptado su ofrecimiento. Se sucedieron los saludos de práctica. Por una frecuencia radial preconvenida, el oficial informó la salida de la nave a los miembros de seguridad embarcados. La embarcación se fue alejando lentamente. El matrimonio se veía alegre. Ella, en la plenitud de su juventud, y él, pletórico al timón de su pequeño crucero. No habían hecho un tramo de cincuenta metros cuando una potentísima explosión despedaza la embarcación, dejando atónitos a los custodios del muelle. No obstante uno de ellos se arrojó al río y consiguió recuperar a la señora de Villar, que había muerto instantáneamente, sufriendo mutilaciones en una pierna. Su marido fue recogido más tarde, pero al haber estado expuesto al grueso de la explosión, su cuerpo había quedado destrozado.

Los relojes de la lancha se habían detenido a la hora 10.50... (Muñoz, 1984:96).

En el final de la historia, lo que importa no es la muerte, sino el asesinato. Es perecer en un atentado lo que activa la fórmula del mártir policial: el sacrificio llega a su pico más alto, pues el caído cae en guerra contra el crimen (Galeano, 2011). Lo mismo dice Muñoz: Villar, "un ser lleno de nobles ideales[,] muere víctima del martirologio propio de su vocación, en defensa del bienestar común" (Muñoz, 1984:98). Lo ejem- 
plar en la vida de Villar, concluye su narrador, es haber sido entregada, en noble sacerdocio, al servicio de la Patria.

Lo dicho para Villar bien puede extenderse a Falcón y a Cardozo: sus historias oficiales son, en realidad, una misma historia, si no en sus detalles específicos, sí en sus líneas generales. Las tres narran, a través de ciertos topoi específicos - el sacrificio, la lucha, el terrorismo, el martirio-, un mismo relato institucional. En estos matices se asienta la razón de su recuerdo. Son estos matices los que convierten sus trayectorias en heroicas, y sus nombres en homenaje. Dedicados, sacrificados, patrióticos, siempre en lucha contra el terrorismo, temerarios, valerosos. Villar (o Falcón o Cardozo) se vuelve espejo de una imagen que refleja no sólo la peligrosidad de la labor policial, sino, aun a pesar de ello, la entrega inclaudicable en aras del bien común. Su muerte se construye como la entrega última: las características de su deceso lo inmortalizan, transforman su nombre en un compendio de imágenes heroicas.

La muerte de Villar parece configurase como un hito sensible para la institución policial, que entiende que el homenaje debe ser tan importante como expeditivo. Su nombre se perpetúa en la escuela de la que fue director. Pero no sólo su nombre. Lo que se perpetúa es, aún más, lo que este nombre evoca. De modo tal que la evocación no hace sino condensar, en este nombre, un discurso institucionalmente legítimo. Un discurso ético, moral y emotivo que, alternando entre imágenes de heroísmo, sacrificio, extremismo y muerte, comunica y ratifica interpretaciones sobre el tejido social.

Bourdieu (1993) señala que la institución de una identidad es la imposición de una esencia social. Esto es, la asignación de una competencia que tanto expresa esa identidad como la impone, notificando a su portador aquello que tiene que ser. En diciembre de 1974, la Escuela de Suboficiales y Agentes recibió el nombre de Alberto Villar. Si el nombre está siempre situado, si su ocurrencia remite a situaciones y contextos particulares, decir Villar - el hombre, la Escuela - es decir, cada vez, "lucha contra la subversión" y "atentado terrorista". Ese nombre se vuelve su sinónimo.

\section{A MODO DE CONCLUSIÓN: LA DISPUTA POR LA HISTORIA Y LA MEMORIA}

Si sobre esta sinonimia se funda el homenaje, sobre ella se asienta también la causa del renombramiento. Ya hemos afirmado que todo lo que 
es dicho, todo lo que es recordado y exaltado, produce comunidad. Todo nombre encripta información, aglutina historia, describe un mito (Cruikshank, 1990). Todo nombre, si se quiere, ayuda a pensar el pasado y, en estrecha relación con éste, provee pistas para pensar el presente (y su particular relación con ese pasado). Todo nombre que persista en el tiempo traza una continuidad, ya sea histórica, política o ideológica.

Comulgar con esta afirmación implica aceptar que las palabras - los nombres - no son meros artefactos pasivos, sino reveladores de un universo ideológico. Su elección nunca es ingenua, en tanto su función se acerca más a lo performático que a lo meramente declarativo. Basta, si no, realizar otro ejercicio de acercamiento y desnudar, aunque sea brevemente, el proceso selectivo que culminó en la elección de los nombres de O’Gorman, Fentanes y Pirker.

Llegué a descubrir esa trama un poco por casualidad. Ya iniciada la escritura de este trabajo, me surgió una pregunta tangencial pero - para mí - importante: ¿cuál era el nombre, si lo había, que tenía la Escuela de Suboficiales y Agentes antes de que le fuera adjudicado el de Villar? La pregunta que subyacía a ésta era anterior y más vital: ¿cuál sería la historia profesional de quién había sido desplazada por la del policía asesinado en 1974? Contaba con que tal respuesta pudiera darme algunas claves acerca de los criterios que cimentaban la elección de los nombres y, sobre todo, acerca de la relación de éstos con el contexto histórico-político en que tal elección tenía lugar ${ }^{21}$.

Luego de consultar sin éxito varios volúmenes de historia institucional, me dije que el único lugar con probabilidades de saciar esta curiosidad era el Centro de Documentación Histórico de la PFA, un lugar atestado de libros y de antiguos profesionales de la fuerza. Me recibió una secretaria que desconocía la respuesta que buscaba, pero que me recomendó hablar con su jefe en el Museo Policial. Saqué papel y lápiz para tomar nota de su nombre. Cuando me dijo de quién se trataba, el intento de fijarlo en la memoria se volvió superfluo. Su jefe era Eugenio Zappietro, uno de los autores de los volúmenes de historia policial que había consultado y un prolífico hombre de letras. Comisario inspector retirado y actualmente Jefe de la División Museo Policial e Investigaciones Históricas de la PFA, Zappietro también supo ser, bajo el pseudónimo de Ray Collins, allá entre los años 1960 y 1980, el guionista de reconocidas historietas. 
La charla con Zappietro no zanjó mi duda, pues no parecía haber existido otro nombre antes del de Villar. Pero me puso delante de otra cuestión aun más importante: él había sido la persona consultada por el equipo de trabajo de la Ministra Garré en la elección de los nuevos nombres que habrían de llevar las escuelas policiales. Zappietro me relató cómo se acercaron a él desde el Ministerio y le pidieron asesoramiento con la elección de tres nombres policiales. Los tres finalmente elegidos, recalcó Zappietro, no fueron los únicos propuestos. Antes de que el nombre de Enrique O'Gorman saliera al ruedo, éste propuso otros. El del comisario general José Gregorio Rossi entre ellos, Jefe de Investigaciones de la entonces Policía de la Capital a principios del siglo XX y artífice de varias innovaciones y procedimientos técnicos (la scopometría y la cédula de identidad, por nombrar sólo dos de los más reconocidos). La propuesta no prosperó porque, según las propias palabras del narrador de la historia, "el nombre no les sonaba". Quedaron finalmente "encantados" con el de O’Gorman.

El propio Zappietro redactó una corta biografía de cada uno de los policías elegidos. Es dable asumir que fue la misma que el Ministerio utilizó, posteriormente, en la redacción del texto de la Resolución 167/2011. Para continuar la argumentación a partir del caso paradigmático antes elegido - la Escuela de Suboficiales y Agentes -, así presentaba Zappietro a Enrique O’Gorman:

Un eficiente funcionario nacido en Buenos Aires el 11 de noviembre de 1823, de reconocida honestidad y eficiencia, accedía a la Jefatura de Policía el 19 de noviembre de 1867, cargo que desempeñaría hasta 1874, para pasar luego a ser Director General de Rentas de la Provincia de Buenos Aires y primer Director de la flamante Penitenciaría Nacional.

Sin experiencia previa, el hermano de la infortunada Camila O’Gorman, fusilada por orden del entonces gobernador Rosas, enfocó la modernización policial desde los cimientos: anuló edictos vigentes y promulgó otros dentro de sus atribuciones para mantener el orden público, alterado por vándalos que en la vía pública destruían las llaves de riego o se bañaban en depósitos o filtros de provisión de agua potable, en tanto dispuso que los oficiales de policía que no usaban uniforme (sólo los agentes y los suboficiales lo hacían) tuviesen una credencial que los identificara como tales y liquidaba la existencia de cepos en las Comisarías, por considerarlos instrumentos de tortura ${ }^{22}$.

La charla con Zappietro no contestó aquella pregunta original, pero puso a mi alcance nuevas consideraciones. Poner en relación al 
O’Gorman que quedó con el Rossi que no fue permite subrayar el carácter selectivo de tales nombres y permite, más aún, desnudar la dinámica que guía tal proceso de búsqueda y elección. El rechazo de Rossi sugiere que el nombre elegido debía, tal vez, sonar conocido. Esto es, debía evocar rápidamente una semblanza: debía despertar, en el conjunto de la sociedad, al menos el esbozo de una imagen. La aceptación de O'Gorman sugiere que - ¿quizás a causa de su hermana Camila? ${ }^{23}-$ ese nombre cumplía el requisito de ya resonar en la memoria argentina. Los breves trazos de su trayectoria profesional no hicieron sino acrecentar el beneficio: cargaban, al nombre ya conocido, con rasgos evidentemente atrayentes para la actual función ministerial. O'Gorman, se nos dice claramente, es contrario a la tortura.

Las idas y venidas de tal proceso selectivo revelan el curso de la estrategia política. Que el nombre debía estar medianamente anclado en la sociedad lo prueba el hecho de que Pirker, como me señalaba oportunamente Zappietro, fue "aceptado enseguida" y entusiastamente por la gente del Ministerio, a causa seguramente de la buena imagen que dejó en la población. Zappietro aseveraba esto y deslizaba, a continuación, una afirmación por lo bajo, hecha casi en confidencia: "nosotros [refiriéndose a la fuerza policial] no compramos esa imagen".

Fuera o no Pirker el policía que la comunidad creía que era - se recordarán las palabras de Palomas Alarcón -, lo interesante de esta declaración es que permite confirmar, una vez más, el carácter construido de la memoria, donde lo definitorio no pasa, necesariamente, por la veracidad del hecho a recordar. Que el nombre buscado por el Ministerio debía estar asociado a ciertas acciones (y alejado de otras) era entonces evidente para Zappietro, que se alegraba de no haberles llegado a proponer otra figura - "ihubiera sido terrible!" -, pues posteriormente se había enterado de que uno de sus descendientes "estaba preso por setentista" 24 .

Todos estos ejemplos - los exitosos y los fallidos - no hacen sino revelar, en consecuencia, los ejes por los que es pasible que discurra la memoria construida. Tal reflexión habilita preguntas necesarias: ¿sobre qué hechos resaltados, soslayados u omitidos se construye entonces el recuerdo? ¿Cuál es el contexto de emergencia y provecho de un determinado homenaje? ¿Cómo y para quién ${ }^{25}$, en definitiva, se construye el mito? 
O'Gorman sumaba, a las ventajas ya descritas, otro detalle de alta significación para la propuesta política de la gestión de Garré: era un funcionario sin experiencia previa. Es decir, no era militar, ni policía de carrera, sino "civil". A su gestión honesta y eficiente, alejada de la coacción al detenido, se le suma (¿a causa de esto?) su origen ajeno a la institución. O'Gorman demuestra, en tal semblanza, que es posible - y de qué forma - la conducción de la fuerza policial a manos de un hombre proveniente de la sociedad civil.

Aunado a la designación de profesionales "civiles" en la cartera ministerial, el mensaje que se quiere dar a la ciudadanía no puede ser más claro. Basta, si no, reparar en que fue justamente un "civil", el subsecretario de Gestión y Bienestar del Personal de las Fuerzas Policiales y Seguridad, Gustavo Palmieri, quien presidió el acto de jura de la bandera de los alumnos del primer año de la Escuela de Cadetes de la PFA el 20 de junio de 2011. Hilando la significación de la jura con su futuro rol de garantes de los derechos ciudadanos, Gustavo Palmieri cerró su discurso de la siguiente manera:

No quiero terminar estas palabras sin hacer alusión a un momento particular de la historia de la que Ustedes, cadetes, ya son protagonistas. Hoy es la primera jura de la bandera que se realiza en la Escuela de Cadetes bajo el nombre del Comisario General Juan Ángel Pirker.

El Comisario General Pirker fue Jefe de la Policía Federal entre junio de 1987 y febrero de 1989. Murió trabajando en el edificio de la Jefatura. Fue un firme batallador por la integración de la institución con la sociedad, y el servicio a la comunidad como estandarte del trabajo policial.

Hoy me interesa destacar una de las características fundamentales del Comisario General Pirker, razón en gran parte de su reconocimiento. Su gestión mostró la capacidad de operar sobre una situación difícil, para transformarla en un desafío y en un logro. Porque el Comisario General Pirker asumió la jefatura en un contexto para nada fácil.

Pirker representa el policía de los desafíos. En apenas un año y medio, en un contexto convulsionado, logró revertir la imagen policial y que su sepelio fuera acompañado por la población en las avenidas.

Pirker desarticuló bandas, luchó contra corrupción, logró un 90\% de esclarecimiento de los homicidios aunque decía que su preocupación era el $10 \%$ de asesinos que habían quedado sueltos. Porque Pirker sabía que el eje de la misión policial no era luchar contra la violencia con más violencia, sino generar estrategias para reducirla. 
Pirker asumió que el poder de la policía se basaba en el entendimiento de la lógica democrática y en una percepción aguda de lo que la sociedad reclamaba de la Policía Federal Argentina.

Hoy, juran la bandera siguiendo esos mismos valores, porque esta debe ser la escuela de esos desafíos ${ }^{26}$.

Las palabras de Palmieri son claras. El nuevo nombre de la escuela implica la señalización de un nuevo comienzo: aquel guiado por nuevos valores - los de Pirker -, que construyen, a su vez, nuevos desafíos - no luchar contra la violencia con más violencia, sino generar estrategias para reducirla. En eso se asienta la nueva narrativa.

Es en este contexto de significación que la resolución 167 / 2011 se vuelve importante para el análisis. No porque se entienda que su implementación opere un cambio de fondo sobre la realidad de la instrucción policial argentina - como si cambiar el nombre de las cosas las cambiara de por sí-, sino porque se entiende que su ejecución construye nuevos sentidos allí donde antes existían otros. Así, esta renarrativización no sólo implica una revisión del relato sino, en virtud a esto, una intervención en la configuración de la memoria social, entendida ésta como un proceso de construcción sociopolítico de la historia, como una "constelación móvil y multivocal de narrativas públicas afiliadas con concepciones e interacciones de grupos e individuos" (Nagy, 2004:640).

Posicionar el análisis en esta operación semántica no implica desconocer la pregunta acerca del "rédito" o "intencionalidad política" de esta medida - ¿es la renominación una tentativa de reforma y de intervención en el discurso público o una simple cortina de humo para la gilada $?^{27}-$, sino poner el foco en una doble cuestión: en su carácter de intervención discursiva y en su entendimiento socio-político como contienda simbólica. Si el primer movimiento opera construyendo sentidos ligados a la historia y la memoria, y abriendo el diálogo sobre las condiciones del presente y el futuro (Connerton, 1989), el segundo, que se le sobreimpone, actúa presentando esos sentidos en una relación de enfrentamiento con otros anteriores. Es decir, actúa disputando autoridades y significados en un determinado espacio de relaciones sociales (Thompson, 1989). Actúa disputando ideología.

La resolución 167 / 2011 ha logrado ser presentada y codificada, desde el discurso político y social, como una cuestión atravesada por la militancia política de los años 1970: su sentido en tanto ley resulta indisociable 
de ese escenario político, delineando un discurso que tanto se inicia como se agota en esos términos. Esto, que para algunos constituye un discurso cerrado y limitativo, parece revelarse también como la fuente de su potencia. Aprovechando, apropiando y utilizando este clima de época ${ }^{28}$, operando sobre y desde la coyuntura política ${ }^{29}$, resulta quizás innegable que es desde esta configuración qua contienda simbólica entre represión y democracia, entre dictadores y montoneros - que la mencionada resolución construye su sentido.

Señalar esta particularidad no invalida el interés sobre el que este trabajo se asienta: el de interrogarse por la construcción de sentido que trama la medida. Su valor radica en lo simbólico: la promulgación de la resolución 167/2011 es la operación de una distancia. No entre meros personajes de la historia - entre Villar y O'Gorman, entre Cardozo y Fentanes, entre Falcón y Pirker -, sino, más aún, entre los significados, los relatos, la historia y la memoria que se construyen en torno a ellos. Después de todo, como bien señala de Pina Cabral (2008), nombrar es reivindicar.

(Recebido para publicação em novembro de 2012)

(Reapresentado em julho de 2013)

(Aprovado para publicação em agosto de 2013) 


\section{Mariana Sirimarco}

\section{NOTAS}

1. La Policía Federal Argentina es la principal fuerza de seguridad del país. Cumple sus funciones en el territorio nacional - a través de delegaciones que pueden actuar conjuntamente con las policías provinciales - y en la Ciudad Autónoma de Buenos Aires - donde ejerce funciones locales junto a la Policía Metropolitana. En Argentina, el costado represivo y criminal de la policía - casos de corrupción, gatillo fácil, muerte de detenidos en comisarías, vínculos con el crimen organizado - la han vuelto una institución tan desprestigiada como temida. Los límites de este trabajo impiden dar cuenta de este estado de la cuestión. Para una mayor profundización acerca del accionar y la historia reciente de las fuerzas policiales argentinas, ver, entre otros, Tiscornia, 1997, 1999, 2008; Eilbaum, 2008; Frederic, 2008; Pita, 2010; Sain, 2008, 2010; Barreneche, 2010, 2011; Dewey, 2011.

2. Decreto $1993 / 2010$.

3. La seguridad en Argentina es gestionada simultáneamente por el Estado Nacional y por las provincias, siendo un caso especial el de la ciudad de Buenos Aires, cuya seguridad está mayormente en manos de la PFA.

4. En: http://es.wikisource.org/wiki/Discurso_de_Cristina_Fernández_en_el_Día_ Universal_de_los_Derechos_Humanos

5. Nilda Garré fue designada Ministra de Defensa el 28/11/2005 por el entonces Presidente de la Nación, Néstor Kirchner.

6. Ver nota 12 , más adelante.

7. Por ejemplo, denuncias penales contra exefectivos por delitos de cohecho y enriquecimiento ilícito, pase a retiro de varios policías de la PFA, entre ellos, su máximo responsable, el comisario general Néstor Valleca.

8. Lo mismo había sucedido años atrás en el ámbito castrense, cuando fueron retirados los nombres de los generales Pedro Eugenio Aramburu y Eduardo Lonardi de las escuelas de Infantería y Artillería del Ejército Argentino, respectivamente. Ambos militares participaron activamente en la Revolución Libertadora, auto-denominación de la dictadura militar que derrocó al presidente constitucional Juan Domingo Perón en 1955. Aramburu sería luego ejecutado por Montoneros en el acto fundacional de esta organización. Mientras estas escuelas militares quedaron sin denominación, la Escuela de Ingenieros pasó a conocerse como "General Juan José Valle", uno de los militares peronistas fusilados en el marco de dicha dictadura en 1956. Similar situación se vivió asimismo en las escuelas de la Policía de la Provincia de Buenos Aires (PPBA). La Escuela de Suboficiales y Tropa fue llamada originalmente "Coronel Julio Dantas", en honor al primer Jefe de la PPBA, creada el 13 de diciembre de 1943 a partir de la antigua Policía de Buenos Aires, de la que también ocupaba la Jefatura. El nombre fue cambiado, posteriormente, por el de "Agente Rosendo Matías", quien fue "el primer suboficial que entregó la vida por la comunidad en un enfrentamiento armado con la delincuencia el 27 de octubre de 1904, en Azul". La Escuela Superior de Policía fue nombrada originalmente a partir del Coronel Adolfo Marsillach, durante cuya Jefatura (1946-1951) se recreó. Posteriormente, en junio de 2000, su nombre fue cambiado para honrar al Comisario Mayor Emilio García García, ascendido post-mortem, por su "heroísmo en los actos consumados en el copamiento al Regimiento III La Tablada [quien,] al intentar recuperar el mencionado Regimiento, pierde su vida" (www.mseg.gba.gov.ar/forycap/institutos). La única escuela que no cambió su nombre es la Escuela de Cadetes "Juan Vucetich", nominada así en honor 


\section{Reformas Policiales y Narrativas Institucionales en Argentina}

al policía que desarrolló el sistema identificador de personas. La política de denominación de la PPBA parece seguir, como se ve, otros carriles. Sobre todo a partir de los renombramientos que eligen, tanto en el caso de la Escuela Superior como en el caso de la de Suboficiales y Tropa, ligar los establecimientos educativos a personajes fallecidos sí en cumplimiento del deber, pero en situaciones que implicaron arriesgar su vida para la defensa de la sociedad. El resultado es una imagen más ligada a la ciudadanía y, si se quiere, menos asociada al ámbito castrense.

9. Dra. Andrea Palomas Alarcón, 18/04/11. En: http://www.lahistoriaparalela.com. ar/2011/04/18/victimas-que-molestan/

10. "Garré degrada a Villar, ese 'buen policía'", José Pablo Feinmann, Diario Página/12, 24/04/11.

11. Tales opiniones deben leerse en concordancia con la existencia de una cierta polarización en la percepción del contexto político, que tiende a leer dicho espectro en términos de adherencia o rechazo al actual sistema de gobierno "kirchnerista".

12. Nilda Garré fue miembro de la Juventud Peronista y estuvo casada con Juan Manuel Abal Medina. Su cuñado, Fernando Abal Medina, fue unos de los fundadores de Montoneros.

13. La alusión es a la teoría que intenta explicar lo sucedido durante la década de los años 70 como una lucha entre dos demonios comparables: las Fuerzas Armadas y las organizaciones guerrilleras.

14. Organización armada alineada en la izquierda peronista, de actuación en la década de los 70. Fue declarada ilegal en 1975.

15. A lo largo de su historia, la PFA estuvo, muchas veces, bajo manos militares. Para dar una rápida ilustración, baste decir que, en el lapso que va desde su creación a la restauración democrática en 1983, el 77\% de sus jefes provenían del ámbito castrense.

16. En las semblanzas que siguen a continuación se privilegian aquellas características señaladas en la Resolución 167 / 2011, por entender que es desde allí que se construye el relato institucional que habrá de servir de contraposición al de los anteriores jefes policiales.

17. Esto es lo que asegura el relato institucional. Hace unos meses, haciendo trabajo de campo en relación a otra temática, una trabajadora sexual me relató que la muerte de Pirker tiene lugar inmediatamente después de haber desarmado una importante red de corrupción en una comisaría del barrio de Flores.

18. Mote que recibía la pareja de cadetes de policía (Cuerpo creado por Falcón) que recorría la zona céntrica con fines de vigilancia y control. El calificativo que acompaña a la denominación da plena cuenta de las características de ese patrullaje.

19. Según los distintos documentos y fuentes consultadas, antes de esa fecha sólo era conocida como "Escuela de Suboficiales y Agentes". Volveré sobre esto más adelante.

20. Cartilla de estudio correspondiente a la materia "Historia policial", Curso Preparatorio para Agentes, año 1999, Escuela Federal de Suboficiales y Agentes "Comisario General Alberto Villar", PFA.

21. Según consta en un diario nacional, que el nombre de la Escuela Superior sea ahora el de Enrique Fentanes y ya no el de Cesáreo Cardozo no obedece tanto a una renominación como a una suerte de "revancha", pues "la Escuela Superior llevaba su nombre hasta que la última dictadura decidió homenajear a Cesáreo Cardozo, que no venía de las filas policiales sino que era general del Ejército" (Videla, Eduardo: "Tres escue-

DADOS - Revista de Ciências Sociais, Rio de Janeiro, vol. 56, 꾸 3, 2013 


\section{Mariana Sirimarco}

las policiales sin la marca de represores", Diario Página/12, 16/04/11). De ser así (no he encontrado en las historias policiales detalle de este hecho), lo aquí argumentado no hace sino sostener la viabilidad de la pregunta que me hiciera anteriormente.

22. Agradezco al Dr. Eugenio Zappietro la gentileza de cederme el texto por él redactado.

23. Proveniente de una familia de clase alta, Camila O'Gorman fue fusilada, estando embarazada, junto al sacerdote Ladislao Gutiérrez, a causa de la historia de amor que los unía.

24. No puede dejar de destacarse lo pertinente entonces que resulta, en la construcción de la narrativa con que se interviene el campo policial, la figura del funcionario Miguel Ángel Robles, cuyo padre se descubre asesinado por la propia policía y no por montoneros.

25. Esta última pregunta adquiere particular relevancia si se señala que, al decir del propio Zappietro, la figura de Alberto Villar no era una especialmente defendida por los integrantes de la agencia policial, a casusa de su accionar profesional. Para profundizar en torno al rol que juegan estas "figuras molestas" en el proceso de construcción de la propia memoria institucional y en cómo este proceso es alentado u obturado por la intervención de los aparatos gubernamentales, ver Badaró, 2009.

26. En: http://www.minseg.gob.ar/index.php/comunicacion/discursos/284-discurso-de-gustavo-palmieri-en-la-primera-jura-de-la-bandera-en-la-escuela-de-cadetes-comisario-general-juan-angel-pirker

27. Este interrogante se abre a otro, mucho más profundo, que pone el énfasis en el control político de las fuerzas policiales, interrogándose acerca del alcance de la modernización democrática de las fuerzas policiales locales. Esta empresa analítica, pasible de futuras reflexiones, excede los límites e intereses concretos de este trabajo.

28. En los días en que escribo este trabajo está a punto de estrenarse, en un canal de televisión abierta, una miniserie acerca del peronismo ("El aluvión"). Unas semanas atrás, una reconocida actriz y vedette se vio envuelta en una suerte de escándalo cuando salió a la luz, en los programas de espectáculos, un hecho hasta ahora tan comentado como acallado: su relación sentimental, durante la última dictadura, con el Almirante Emilio Massera, integrante de la junta militar durante 1976-1978. Que tales temáticas adquieran visibilidad en ciertos canales y en ciertos programas de televisión configura, creo yo, un clima de época.

29. En este saludable afán de revisionismo, tal vez no sea superfluo preguntarse por las implicancias de subsumir, de forma acrítica y lineal, a todo funcionario de la última dictadura militar en el esquema político represivo del momento. Pienso, por ejemplo, en el caso trabajado por Spivak L'Hoste en relación a la Comisión Nacional de Energía Atómica. La autora relata que, en el acto de "La Memoria, la Verdad y la Justicia a Treinta años del Golpe Militar" realizado en 2006, se retiró del hall de acceso a las oficinas de las autoridades la foto del Almirante Carlos Castro Madero, quien fuera presidente de la Comisión durante todo el período dictatorial. Lo interesante del caso, a decir de la autora, es cómo este episodio invisibilizó, bajo un manto homogéneo de repudio, acciones llevadas a cabo por dicho funcionario y rescatadas por los trabajadores de la Comisión: desde su rol en el impulso del desarrollo nuclear en el país hasta acciones tendientes a protegerlos de las consecuencias del terrorismo de estado (Spivak L'Hoste, comunicación personal). Sin ánimos de pretender equiparar este suceso con lo narrado aquí en relación al ámbito policial, no deja de ser interesante preguntarse por los alcances y las implicancias que puede conllevar la traducibilidad inmediata del funcionario de la dictadura en términos de represor. 


\section{Reformas Policiales y Narrativas Institucionales en Argentina}

\section{BIBLIOGRAFÍA}

BADARÓ, Máximo. (2009), Militares o Ciudadanos. La Formación de los Oficiales del Ejército Argentino. Buenos Aires, Prometeo Libros.

BARRENECHE, Osvaldo. (2010), “De Brava a Dura. La Policía de la Provincia de Buenos Aires durante la Primera Mitad del Siglo XX". Cuadernos de Antropología Social, no 32, pp. 31-56.

(2011), “Construyendo la "Casa de Piedra”. La Policía de la Provincia de Buenos Aires durante la Primera Mitad del Siglo XX", en D. Galeano y G. Kaminsky (coords), Mirada (de) Uniforme. Historia y Crítica de la Razón Policial. Buenos Aires, Editorial Teseo.

BOURDIEU, Pierre. (1993), “Los Ritos como Acto de Institución”, en J. Pitt-Rivers y J. G. Peristiany (coords.), Honor y Gracia. Madrid, Alianza Editorial, pp.111-123.

BRUNER, Jerome. (1991), “The Narrative Construction of Reality”. Critical Inquiry, vol. 18, pp.1-21.

CAVALLARO, Renato. (2000), “Sociología e Storie di Vita: 'Il Testo', Il 'Tempo', lo 'Spazio'”, en M. I. Macioti (ed.), Biografia, Storia e Societá. L'Uso delle Storie di Vita nelle Scienze Sociali. Napoli, Liguori Editore, pp. 63-78.

CONNERTON, Paul. (1989), How Societies Remember. Cambridge, Cambridge University Press.

CRUIKSHANK, Julie. (1990), “Getting the Words Right: Perspectives on Naming and Places in Athapaskan Oral History". Arctic Anthropology, vol. 27, pp. 52-65.

DE PINA CABRAL, João. (2008), “Outros Nomes, Histórias Cruzadas: Apresentando o Debate". Etnográfica, vol. 12, no 1, pp. 5-16.

DEWEY, Matías. (2011), Fragile states, robust structures: illegal police protection in Buenos Aires. Hamburgo, GIGA Working Papers.

EILBAUM, Lucía. (2008), Los “Casos de Policía” en la Justicia Federal en Buenos Aires. El Pez por la Boca Muere. Buenos Aires, Antropofagia.

(2004), “'La Policía al Servicio de la Comunidad': Tradición Policial y Vientos de Cambio", in S. Tiscornia (comp.), Burocracias y Violencia. Estudios de Antropología Política. Buenos Aires, Antropofagia.

FOLEY, John Miles. (1992), “Word Power, Performance and Tradition”. The Journal of American Folklore, vol.105, no 417, pp. 275-301.

FORD, Robert. (2003), "Saying One Thing, Meaning Another: The Role of Parables in Police Training". Police Quarterly, vol. 6, no 1, pp. 84-110.

FREDERIC, Sabina. (2008), Los Usos de la Fuerza Pública. Debates sobre Militares y Policías en las Ciencias Sociales de la Democracia. Buenos Aires, Biblioteca Nacional-Universidad Nacional de General Sarmiento.

GALEANO, Diego. (2011), “'Caídos en Cumplimiento del Deber'. Notas sobre la Construcción del Heroísmo Policial”, en D. Galeano y G. Kaminsky, Mirada (de) uniforme. Historia y Crítica de la Razón Policial. Buenos Aires, Editorial Teseo, pp. 185-219.

DADOS - Revista de Ciências Sociais, Rio de Janeiro, vol. 56, 꾸 3, 2013 


\section{Mariana Sirimarco}

HERZFELD, Michael. (1982), “The Etymology of Excuses: Aspects of Rhetorical Performance in Greece". American Ethnologist, vol. 9, no 4, pp. 644-663.

JELIN, Elizabeth. (2007), “Víctimas, Familiares y Ciudadanos / as: Las Luchas por la Legitimidad de la Palabra". Cadernos Pagu, vol. 29, pp. 37-60.

MUÑOZ, Jorge. (1984), Seguidme! Vida de Alberto Villar. Buenos Aires, Ediciones Informar.

NAGY, Rosemary. (2004), "After the TCR: Citizenship, Memory, and Reconciliation". Canadian Journal of African Studies, vol. 28, no 3, pp. 638-653.

OCHS, Elinor y CAPPS, Lisa. (1996), "Narrating the Self". Annual Review of Anthropology, vol. 25 , pp. 19-43.

PITA, María Victoria. (2010), Formas de Morir y Formas de Vivir. El Activismo contra la Violencia Policial. Buenos Aires, Editores del Puerto \& CELS.

SAIN, Marcelo. (2008), El Leviatán Azul. Policía y Política en la Argentina. Buenos Aires, Siglo XXI Editores.

(2010), La Reforma Policial en América Latina. Una Mirada Crítica desde el Progresismo. Buenos Aires, Prometeo.

SIRIMARCO, Mariana. (2010), “Memorias Policiales. Narrativas de Emotividad”. Publicar-En Antropología y Ciencias Sociales, vol. VIII, pp.127-143.

SPIVAK L'HOSTE, Ana. (2010), El Balseiro. Memoria y Emotividad en una Institución Cientifica Argentina. La Plata, Ediciones Al Margen.

THOMPSON, Edward Palmer. (1989), Tradición, Revuelta y Conciencia de Clase. Estudios sobre la Crisis de la Sociedad Preindustrial. Barcelona, Editorial Crítica.

TISCORNIA, Sofía. (1997), "La Seguridad Ciudadana y la Cultura de la Violencia". Encrucijadas. Revista de la Universidad de Buenos Aires, no 5, pp. 17-29.

. (1999), “Violencia policial en Capital Federal y Gran Buenos Aires. Cuestiones Metodológicas y Análisis de Datos", en M. Sozzo (comp.), Seguridad Urbana. Nuevos Problemas, Nuevas Perspectivas. Pensar Alternativas Teóricas y Políticas sobre la Cuestión Criminal. Santa Fe, Centro de Publicaciones, Universidad Nacional de Litoral.

. (2008), El Activismo de los Derechos Humanos. El Caso Walter Bulacio. Buenos Aires, Editores del Puerto/CELS.

TONKIN, Elizabeth. (1980), “Jealousy Names, Civilised Names: Anthropology of the Jlao Kru of Liberia". Man, vol.15, pp. 653-664. 


\author{
ABSTRACT \\ Police Reforms and Institutional Narratives in Argentina: Renaming \\ Police Training Schools
}

In April 2011, Argentina's Minister of Public Security issued a ruling to change the names of Federal Police training academies, eliminating the homage to police chiefs associated with police repression and renaming the schools for officers associated with human rights protection. Based on an analysis of various documents and media sources, the current article argues that words themselves can "create" and "sustain" social relations and situations, since they communicate identities and allow experimentation with reality. The current study thus aims to examine the symbolic implications of these reforms, unveiling their discursive and evaluative plots and discussing the weight and scope of the country's police reforms and attempts to adjust to the current political context. The conclusions include some uses and appropriations of history and memory.

Key words: Argentina; reforms; police; schools; names

\title{
RÉSUMÉ
}

Réformes Policières et Récits Institutionnels en Argentine: Les Nouveaux Noms des Écoles de Police

En avril 2011, la Ministre de la Sécurité en Argentine s'est prononcée favorablement pour le changement de nom des écoles de la Police Fédérale argentine, en cessant de rappeler les noms des chefs associés à la répression policière, pour rendre hommage aux officiers soucieux de la préservation des droits de l'homme. Dans cet article, on comprend, à partir de l'analyse de divers documents et articles de journaux, que les mots "créent" et "soutiennent" les rapports et les situations sociales, puisqu'ils communiquent des identités et permettent une certaine expérience de la réalité. Ainsi, on cherche à y examiner ces réformes sur leur plan symbolique d'action, en révélant leur trame de discours et d'évaluation, tout en discutant le poids et le but des réformes policières et leurs tentatives d'adéquation au contexte politique actuel. En conclusion, on présente aussi certains usages et appropriations de l'histoire et de la mémoire.

Mots-clés: Argentine; réformes; police; écoles; noms 